\title{
Realization of smart train crew management with ICT
}

\author{
Y. Sakaue ${ }^{1}$, H. Saiko ${ }^{1}$, Y. Osawa ${ }^{1}$, T. Maniwa ${ }^{2}$, \\ Y. Yamaguchi ${ }^{2} \&$ S. Arisue ${ }^{2}$ \\ ${ }^{1}$ JR East Information Systems Company, Japan \\ ${ }^{2}$ East Japan Railway Company, Japan
}

\begin{abstract}
About 12,000 train crews (drivers and conductors) are engaged in the train operations of East Japan Railway Company (JRE). Everyday roll call operation (attendance/leaving management for train crews) is one of the indispensable duties to enhance safe and reliable transportation services.

Paper roll call lists were used for roll call operations until last spring. Managers had to print out the roll call lists and write down information for the crews by the day before each roll call. When managers take roll calls using lots of paper roll call lists, there are some risks with checking their watches, writing real approval times and examiner names. Because there are about 300 train crews in large crew depots, it has been difficult for new managers to remember all the names of train crews. Some managers set alarm clocks to prevent crews from being late. Owing to these situations, managers couldn't concentrate on their main duties which are making decisions and instructing crews.

To solve these problems, we developed a new function called "Train Crew Working Management" using 21.5-inch slate PCs in July 2015. Those show all the information needed for each roll call operation and identify train crews and managers by ID cards using Near Field Communication (NFC). When train crews are late, the system beeps so that managers can notice. Mistakes have been reduced by this new function. Moreover, managers have been able to concentrate on their main duties. We believe that crew depots' business will become more efficient and smart by expanding this function.

Keywords: train crew management, roll call, ICT, Near Field Communication (NFC).
\end{abstract}




\section{Introduction}

JRE covers the northeastern part of Japan mainly in the Tokyo metropolitan area and five Bullet Train (Shinkansen) lines (Tohoku, Joetsu, Hokuriku, Yamagata, and Akita). Figure 1 shows the service area of JRE. The passenger railway network reaches $7,458.2 \mathrm{~km}$. The total number of trains in operation per day is more than 12,000 and the total number of passengers per day is approximately 17 million. JRE is the biggest private passenger railway company in Japan and maybe in the world.

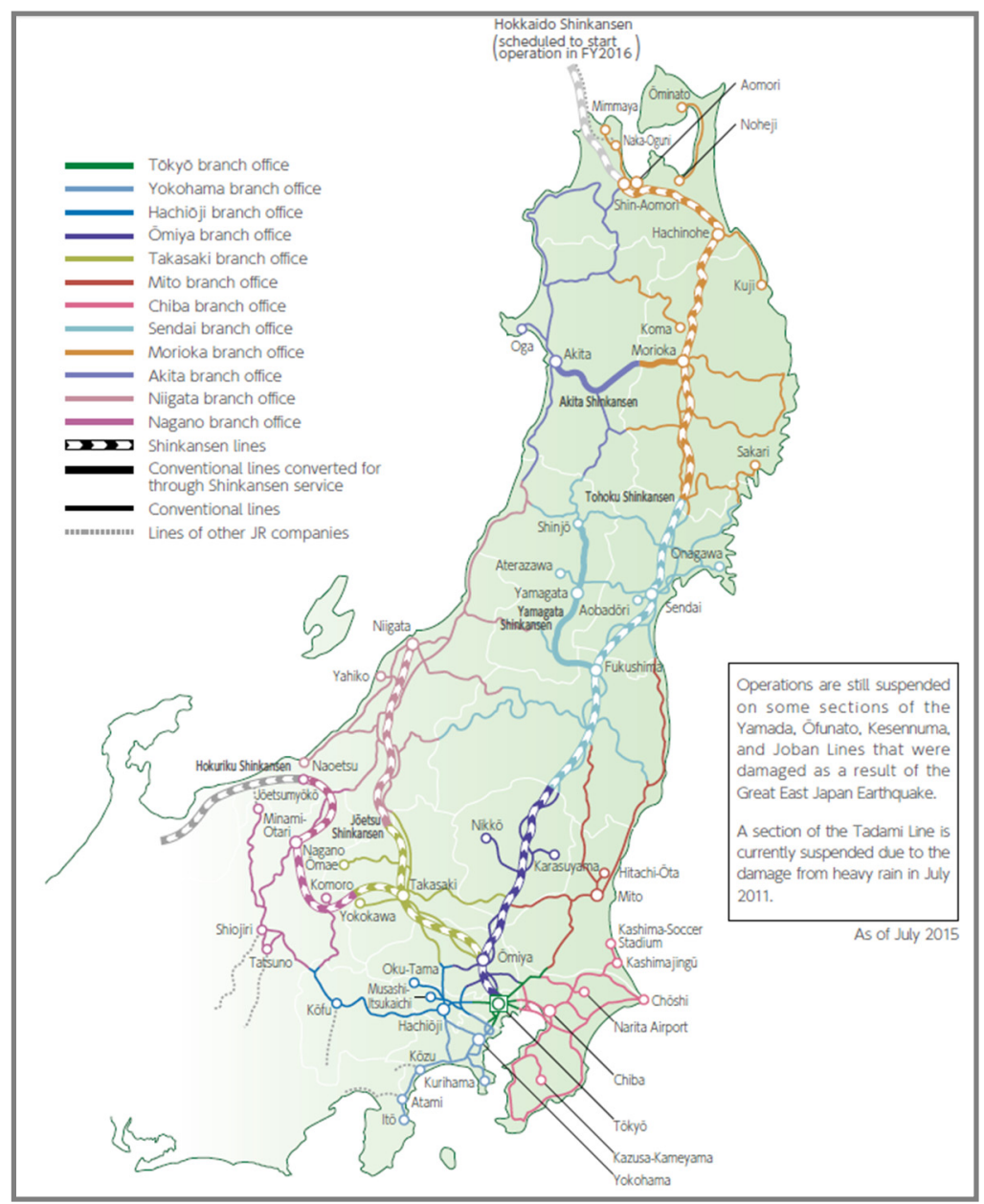

Figure 1: JRE service area [1]. 


\section{IROS overview}

\subsection{IROS overall system}

Integrated Railway Operating System (IROS) totally supports transport planning and train operations of JRE. Concretely, it supports scheduling of train diagrams, rolling stocks management, train crew management, and so on. Since 1990, we have been expanding the functions for a quarter of a century. Nowadays, IROS is indispensable to transport operations in JRE. Figure 2 shows the sub-systems of IROS. "Train Crew Working Management" is one function of Crew Depot Management System.
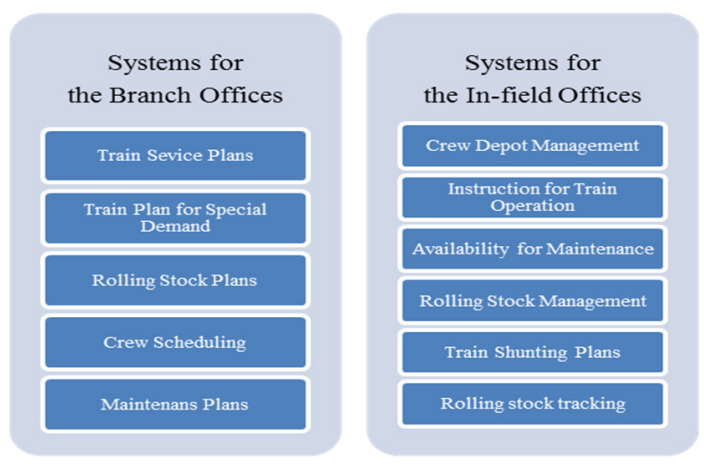

Figure 2: Sub-systems of IROS.

\subsection{Crew Depot Management System}

The Crew Depot Management System provides many essential functions for train crew management such as train crew working management, crew orbit scheduling, crew working result management, and portable time table output for train crews.

Table 1: Main functions of the Crew Depot Management System.

\begin{tabular}{|c|l|l|}
\hline No. & \multicolumn{1}{|c|}{ Function name } & \multicolumn{1}{c|}{ Functional overview } \\
\hline 1 & $\begin{array}{l}\text { train crew working } \\
\text { management }\end{array}$ & $\begin{array}{l}\text { Managing the attendance/leaving of train } \\
\text { crews. }\end{array}$ \\
\hline 2 & crew orbit scheduling & $\begin{array}{l}\text { Making drivers and conductors scheduling } \\
\text { plans. }\end{array}$ \\
\hline 3 & $\begin{array}{l}\text { crew working result } \\
\text { management }\end{array}$ & $\begin{array}{l}\text { Managing crew working results of train } \\
\text { crews. }\end{array}$ \\
\hline 4 & portable time table & $\begin{array}{l}\text { Print out and manage the portable time table } \\
\text { for train crew. }\end{array}$ \\
\hline
\end{tabular}




\section{Roll call duty of JRE}

\subsection{Characteristics of roll call duty in JRE}

Approximately 12,000 train crews are enrolled in JRE. There are about 100 train crew depots. In big train crew depots, 3 to 4 managers manage approximately 300 train crews. Each train crew has to be taken roll call more than twice a day. Mostly attending and leaving roll call moments for each train crew are different and those differ every day. During rush hours, the train crews attend at intervals of 1 minute. In some cases, managers must roll-call two train crews at the same time. When a train crew comes late, it leads train delay. And if a manager omits to tell an instruction for a train crew, it incurs a risk of train accident. Therefor roll call management is one of the most important duties to enhance safe, reliable, and punctual transportation services.

Table 2: $\quad$ Example of roll call time in a certain crew depot.

\begin{tabular}{|c|c|c|}
\hline Duty No. & Estimated roll call time & Name of the train crew \\
\hline B1 & $8: 30$ & Sato \\
\hline B2 & $8: 33$ & Suzuki \\
\hline C1 & $8: 35$ & Takahashi \\
\hline B3 & $8: 37$ & Tanaka \\
\hline C2 & $8: 38$ & Ito \\
\hline C3 & $8: 41$ & Watanabe \\
\hline B4 & $8: 45$ & Yamamoto \\
\hline B5 & $8: 59$ & Kobayashi \\
\hline B6 & $9: 00$ & Kato \\
\hline C4 & $9: 00$ & Yoshida \\
\hline C5 & $9: 00$ & Yamada \\
\hline C6 & $9: 02$ & Sasaki \\
\hline B7 & $9: 04$ & \\
\hline
\end{tabular}

\subsection{Problems before the introduction of the function}

Managers used paper roll call lists for crew working management until the spring of 2015. Managers needed to print roll call lists and handwrite instructions for train crews by the day before each roll call. There are various instructions for train crews such as "Tokyo station is under construction", "Personal interview will be conducted tomorrow", and so on. Every instruction must be transmitted at a suitable timing. So managers had to handwrite instructions on roll call lists or make instruction lists by themselves to tell instructions without missing anything.

\subsubsection{Attending roll call}

When train crews come to depots, managers check the following things.

- Overview of today's duty.

- Alcoholic inspection test. 
- Holding of glasses and contact lenses.

- Instructions for drivers and conductors.

- Lending goods like tablet computers, keys, etc.

- Various information.

- Adjusting train crews' watches.

- Health condition of train crews.

After all the checks were finished, managers would write down accurate approval times and set their seals to roll call lists. At first, new managers were required to memorize 300 train crews' name at the maximum. Additionally, there were risks of human error like misreading or misinterpreting, because managers must find out suitable instructions from lots of lists. In case of train disturbances, managers wrote the changes of schedules to roll call lists. Since train crews don't always attend in order of estimated roll call times, managers had to check roll call lists and times frequently to make sure that no train crew was late.

\subsubsection{Leaving roll call}

When train crews leave from depots, managers check the following things.

- Overview of the next duty (day and time of the next attendance).

- Returning goods like tablet computers, keys, etc.

- Various information.

Confirming the day and time of the next duty is especially important because each crew's holiday and the next attending time are different.

After leaving roll calls, managers had to file roll call lists and keep them for five years as evidence. In order to check the past records, managers needed to find them from a bunch of papers.

The essential work of managers is supervising train crews' work and checking the physical and mental condition of train crews. And furthermore, managers have to make a contribution to safe and reliable transportation service. As mentioned above, the workload of roll calls was so heavy that managers could hardly concentrate on their essential work. Especially when transport disorder happens, managers need to contact the people involved, plan and instruct various changes while the roll call is held.

\section{Train crew working management function}

\subsection{Overview and characteristic of the function}

To solve the problems described above, we introduced a new function using 21.5inch slate PCs in July 2015. It is called "Train Crew Working Management". Two main screens of this function are shown in figure 3. The "Roll call list" screen shows the names of train crews and estimated roll call times in order of appearance. When train crews come to a depot, they hold their ID cards on a 
reader. Then the system identifies the individual and shows the information needed for the train crew's roll call in "Roll call" screen.

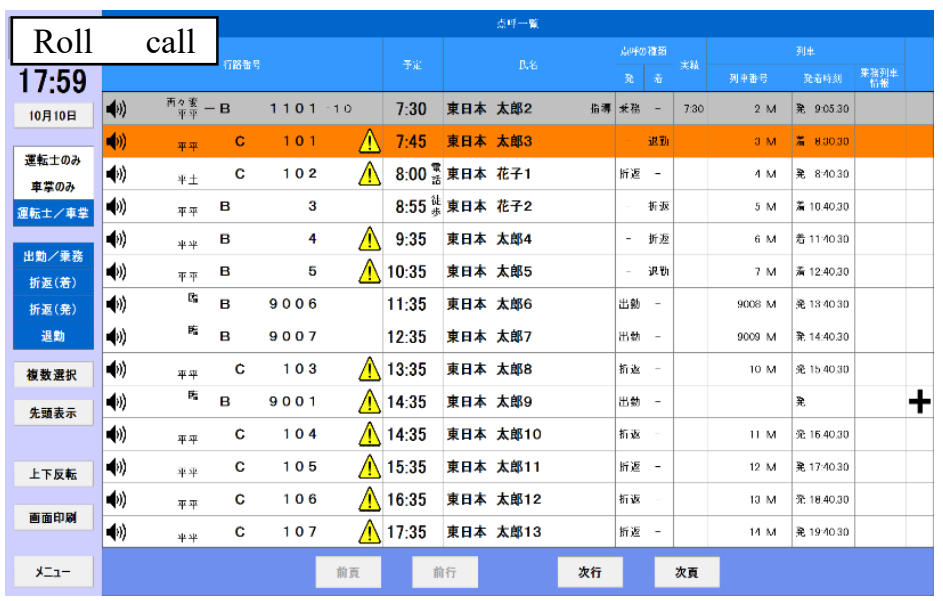

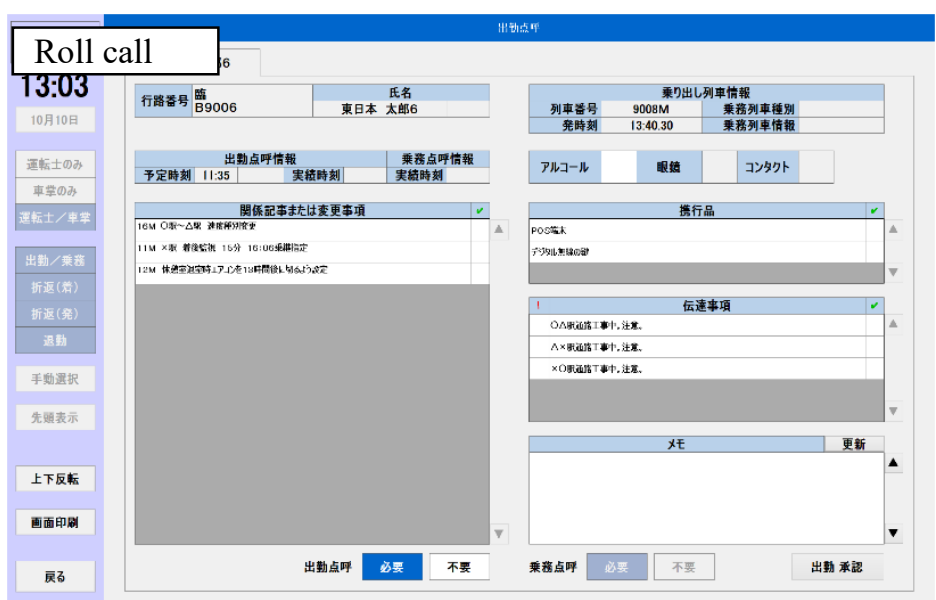

Figure 3: Screen of roll call list and roll call.

Holding goods and instructions for each train crew are different, and in some cases, there would be more than ten of them at one roll call. By registering these things beforehand, only the necessary information will be shown in the "Roll call" screen. Therefore, managers just need to read the information on the screen and tap the screen to check. To meet various needs, arbitrary conditions can be set in many ways in case of pre-registration. For example, only drivers, only conductors, only specific train crew, only in attendance, every roll call in certain period, etc. can be set as conditions.

Managers use their ID cards too. In this way, we realized to record surely who and when approved. When a train crew is likely to be late, the system beeps and warns to managers. In case of transport disorders, information of transportation 
changes may be entered directly to slate PCs, and then managers can take roll calls immediately. Records are archived in the database for 5 years. So managers have become possible to search any record easily and quickly.

\subsection{Effects of the new function}

After the introduction of this function, we went to train crew depots and heard the opinions of users. The following are the effects of the function that they described.

- Printing the roll call list became unnecessary. So managers can concentrate on their essential duty (scheduling, making decisions, and instructing).

- The system authenticates an individual by an ID card. Therefore, especially new managers can identify every train crews without making a mistake.

- Train crews' working hours differ variously every day. Sometime they work from early in the morning and sometime they work from evening to next morning. Mostly they are getting on trains, so they are apart from their crew depots. Therefore, telling instructions at roll calls is vitally important. By using the new slate PCs instead of paper roll call lists, managers' work has been greatly improved.

- The managers don't have to handwrite the time of approval and seal on paper call lists any more. They can take a roll call in a short period without failures.

- The system warns managers by beep sounds and messages. So train delay caused by attendance delay has been prevented.

- By using slate PCs instead of paper roll call lists, paper expenses and carbon dioxide emissions have been reduced.

\subsection{Future prospects}

Train transportation is significant for commuting especially in the Tokyo metropolitan area. But sometime train disorders happen due to various factors like natural disasters and rolling stock troubles and so on. In such cases, managers are required to plan the best changes with related offices, and inform the result to commuters correctly and quickly. To solve these problems, we are considering the following ways and means.

\subsubsection{Roll calls between remote places}

Sometimes roll calls are conducted between remote places using telephones or video phones. So train crews must go to near crew depots to use phones. We are thinking about managing the health of train crews who are in remote places using tablet computers with transmitting videos and vital data.

\subsubsection{Utilization of train crew data}

Managing the mental and physical conditions of train crews is important. Licenses of drivers and conductors are finely classified according to train lines and type of rolling stocks. Instructors manage these licenses. They also teach drivers and conductors not only using textbooks but also real driving with train crews. Instructors have a lot of work to do but they have been using paper lists to manage 
the license of train crews. To resolve this problem, we are considering developing a new system to support instructors.

\subsubsection{Communicating information}

Train crews constantly check the information such as slow down areas, and write down the necessary information in their pocketbook before their roll calls. Instead of writing on papers, we are thinking about using tablet computers. So when transportation changes occur, managers register those to the system and transmit those to train crews via tablets from depots.

\subsubsection{Future vision}

In the future, we would like to connect data with train operating system, crew depots system, and train crews' tablets so that train disorders are recovered smoothly. Figure 4 shows the future prospects as mentioned above.

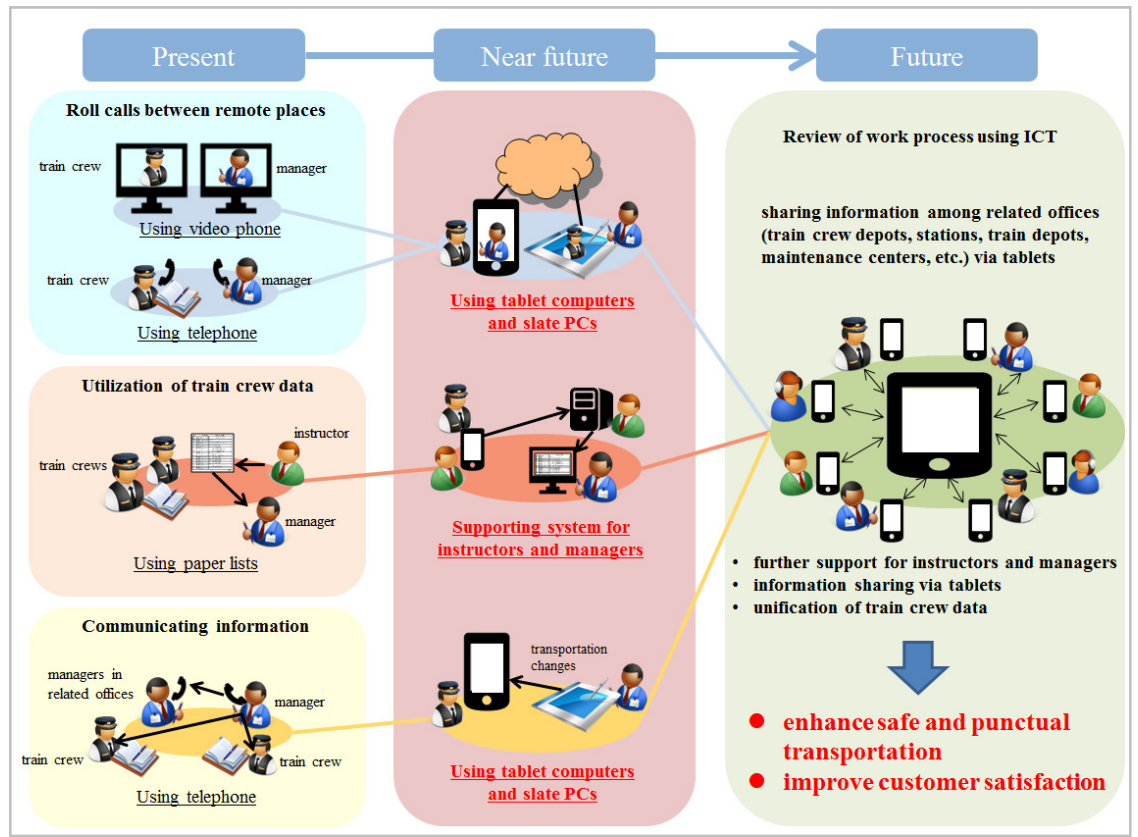

Figure 4: Future prospects.

\section{Conclusion}

"Train Crew Working Management" function manages train crews from attending to leaving at their depots. It was introduced to provide further safety and security to train passengers. This new effort is appreciated by managers and train crews in crew depots. So working at crew depots has been innovatively improved. 
ICT is making remarkable progress in various areas. We want to utilize it fully and provide further new functions which support managers making best decisions at crew depots.

\section{Reference}

[1] East Japan Railway Company "2015 Annual Report", http://www.jreast.co.jp/e/environment/pdf_2015/p121.pdf 